\title{
KOMBINASI METODE ANALITICAL HIERARCHY PROCESS DAN WEIGHTED PRODUCT DALAM PENENTUAN BENIH CABAI UNGGUL
}

\author{
Suci Andriyani ${ }^{1 *}$, Febby Madonna Yuma ${ }^{1}$ \\ ${ }^{1}$ Sistem Informasi, Sekolah Tinggi Manajemen Infromatika dan Komputer Royal \\ email: suciandriyani94@gmail.com
}

\begin{abstract}
Chili consumption in Indonesia continues to increase. Imports are carried out by the government to meet domestic needs such as those from Malaysia and Vietnam. To overcome this chili import problem, it is necessary to maximize the efforts made by local farmers to produce chili yields with optimal quantity and quality. Efforts that can be made besides increasing unproductive agricultural land are applying technology to determine the best / superior chili seeds. So far, local farmers use hereditary concepts such as trial and error in determining the chili seeds to be planted. As a result of which occurs that the harvest is unstable and tends to fall even the possibility of crop failure. The purpose of the analysis of this research is to apply technology that can improve chili crop yields through the application of a Decision Support System. To get more optimal results, the application of technology is carried out using the concept of a combination of 2 methods based on the superiority of each method. The method used is the Analytical Hierarchy Process (AHP) because it has accurate criteria analysis. Furthermore, the Weighted Product (WP) method is applied because it can find alternative preference values that are quick and easy. Based on the process and results of the analysis that has been done, the application of the AHP method can produce priority factors for selecting superior chili seeds that are weighted for ranking WP method. Whereas the WP method can produce an alternative ranking quickly with the highest alternative being A5 with a value of 0.153 .
\end{abstract}

Keywords: Chili Seeds; AHP; Weighted Product; SPK.

\begin{abstract}
Abstrak: Konsumsi cabai di Indonesia terus mengalami peningkatan. Impor dilakukan oleh pemerintah untuk memenuhi kebutuhan dalam negeri seperti dari negara Malaysia dan Vietnam. Untuk mengatasi masalah impor cabai ini, perlu upaya maksimal yang dilakukan oleh petani lokal untuk menghasilkan hasil panen cabai dengan kuantitas dan kualitas yang optimal. Upaya yang dapat dilakukan selain memperbanyak lahan pertanian yang belum produktif yaitu menerapkan teknologi teknologi untuk menentukan benih cabai yang terbaik/unggul. Selama ini petani lokal menggunakan konsep turun temurun seperti coba-coba dalam menentukan benih cabai yang akan ditanam. Akibat yang terjadi yaitu hasil panen yang tidak stabil dan cendrung turun bahkan kemungkinan gagal panen. Adapun tujuan dari analisis penelitian ini adalah untuk menerapkan teknologi yang dapat meningkatkan hasil panen tanaman cabai melalui penerapan Sistem Pendukung Keputusan. Untuk mendapatkan hasil yang lebih optimal, penerapan teknologi dilakukkan menggunakan konsep kombinasi 2 metode yang didasarkan pada keunggulan dari masing-masing metode. Metode yang digunakan Analitical Hierarchy Process (AHP) karena memilki analisis kriteria yang akurat. Selanjutnya diterapkan metode Weighted Product (WP) karena memiliki kemampuan penemuan nilai preferensi alternatif yang cepat dan mudah. Berdasarkan proses dan hasil analisis yang telah dilakukan, penerapan metode AHP mampu menghasilkan faktor prioritas pemilihan benih cabai unggul yang menjadi nilai bobot untuk perankingan metode WP. Sedangkan metode WP mampu menghasilkan perankingan alternatif dengan cepat dengan alternatif tertinggi yaitu A5 dengan nilai 0,153.
\end{abstract}

Kata Kunci: AHP; Benih Cabai; SPK; Weighted Product. 
JURTEKSI (Jurnal Teknologi dan Sistem Informasi)

Vol. 6 No. 2, April 2020, hlm. 117 - 124

DOI: https://doi.org/10.33330/jurteksi.v6i2.596

Available online at http://jurnal.stmikroyal.ac.id/index.php/jurteksi
ISSN 2407-1811 (Print)

ISSN 2550-0201 (Online)

\section{PENDAHULUAN}

Cabai (Capsicum annuum L) tumbuhan yang merupakan sebuah komoditas dengan tingkat kebutuhan masyarakat yang tinggi secara ekonomi sebagai rempah dalam memenuhi kebutuhan sehari-hari [1]. Sebagai sebuah rempah, capai memiliki peranan yang sangat penting dalam masakan khas nusantara yaitu untuk meningkatkan selera makanan. [2]. Konsumsi cabai di Indonesia terus mengalami peningkatan sejak tahun 2016 sebanyak 972.452 ton, tahun 2017 sebanyak 1,051,911, dan tahun 2018 sebanyak 1,137,688. Dalam pemenuhan kebutuhannya, pemerintah sampai melakukan impor seperti dari negara malaysia dan vietnam. Untuk mengatasi masalah impor cabai ini, perlu upaya maksimal yang dilakukan oleh petani lokal untuk menghasilkan hasil panen cabai dengan kuantitas dan kualitas yang optimal. Upaya yang dapat dilakukan selain memperbanyak lahan pertanian yang belum produktif yaitu menerapkan teknologi dalam pertanian cabai. Hal ini untuk menunjang meningkatnya hasil panen. Salah satuya menerapkan teknologi untuk menentukan benih cabai yang terbaik/unggul.

Permasalahannya, selama ini petani lokal menggunakan konsep turun temurun atau yang disebut dengan cara tradisional seperti coba-coba dalam menentukan benih cabai yang akan ditanam[3]. Akibat yang terjadi yaitu hasil panen yang tidak stabil dan cendrung turun bahkan kemungkinan gagal panen. Begitupun petani di Desa Rawang Panca Arga Kabupaten Asahan yang menjadi lokasi observasi, petani masih menggunakan cara coba-coba dan mengandalkan kebiasaan turun temurun dalam menentukan benih cabai yang ditanam. Sebagai contoh masih ada petani memilih benih cabai berdasarkan harga benih yang murah dan yang memiliki masa panen lebih cepat. Namun hal tersebut kurang mampu mengatasi hama yang muncul kapan saja sehingga memung-kinkan menghasilkan hasil panen yang rendah. Selain tonase yang lebih sedikit hal itu juga berpengaruh pada kualitas cabai yang dihasilkan. Dampaknya mengurangi harga jual hasil panen.

Penelitian ini bertujuan menerapkan teknologi yang dapat meningkatkan hasil panen tanaman cabai melalui penerapan Sistem Pendukung Keputusan. Untuk mendapatkan hasil yang lebih optimal, penerapan teknologi dilakukkan menggunakan konsep kombinasi 2 metode yang didasarkan pada keunggulan dari masing-masing metode. Metode yang digunakan Analitical Hierarchy Process (AHP) karena memilki analisis kriteria yang akurat [4], selanjutnya diterapkan metode Weighted Product (WP) karena memiliki kemampuan penemuan nilai preferensi alternative yang cepat dan mudah[5], [6].

Cabai adalah buah dari sebuah tumbuhan yang masuk dalam rumoun Genus Capsium yang popular sebagai rempah makanan yang dapat dijadikan sebagai penguat rasa. Pada benua Asia khususnya Indoinesia, cabai berperan sangat penting dalam sebuah makanan yang dapat menggugah rasa sehingga dapat meningkatkan nafsu makan[7].

Sistem Pendukung Keputusan merupakan sebuah sistem secara komputerisasi yang diperuntukkan untuk menyelesaikan sebuah permasalahan tertentu dengan pendekatan kuantitatif dalam membantu penentu keputusan seperti manajer yang 
DOI: https://doi.org/10.33330/jurteksi.v6i2.596

Available online at http://jurnal.stmikroyal.ac.id/index.php/jurteksi

memudahkannya dalam mengambil keputusan. Sehingga Sebuah permasalahan yang rumit dapat diselesaikan dengan cepat dan proses yang mudah [8].

Analitycal Hierarchy Process adalah sebuah metode pemecahan masalah dalam pengambil keputusan dengan menggu-nakan konsep hirarki dalam menghasilkan sebuah solusi prediktif yang dapat dijadikan sebagai masukan bagi pengambil keputusan [9].

Analisis data ini dimulai dengan menentukan nilai pembobotan kriteria yang konsisten menggunakan metode AHP. Prosedur dalam metode AHP meliputi:

1. Mendefinisikan masalah dalam bentuk hirarki.

2. Menentukan prioritas elemen

Matriks perbandingan berpasangan menggunakan bilangan 1 - 9 untuk mempresentasikan kepentingan relatif dari suatu elemen terhadap elemen yang lainnya.

3. Sintesis

Pertimbangan terhadap perbandingan berpasangan disintesis untuk memperoleh keseluruhan prioritas.

4. Mengukur konsistensi

Bertujuan untuk mendapatkan pertimbangan pada sebuah kriteria dengan konsistensi yang baik.

Hitung Consistency Ratio(CR) dengan rumus:

$\mathrm{CR}=\mathrm{CI} / \mathrm{IR}$

Dimana

$\mathrm{CR}=$ Consistency Ratio

$\mathrm{CI}=$ Consistency Index, $\mathrm{CI}=(\lambda$ maks $-\mathrm{n}) / \mathrm{n}$,

Dimanan $=$ banyaknyaelemen

$\mathrm{IR}=$ Indeks Random

Nilai Indeks Random

5. Consistensi Ratio (CR)

Jika nilainya $\mathrm{CR}<=0,1$ maka nilai

konsistensi sudah baik, sedangkan jika $\mathrm{CR}>0,1$ makapenilaian data judgment harus diperbaiki.

Weighted Product merupakan metode yang popular dalam sistem pendukung keoputusan karena mampu mengatasi permasalahan yang bersifat Multi Attribute Decision Making (MADM). Metode Weighted Product menggunakan perkalian antara nilai atribut (faktor), dengan proses setiap atribut (faktor) terlebih dahuku dipangkatkan dengan bobot atribut (faktor) yang disuai [10].

Preferensi untuk alternatif $\mathrm{Ai}$ dimulai dari mencari nilai vector $\mathrm{S}$ sebagai berikut:

$$
S_{i}=\prod_{j=1}^{n} x_{i j}{ }^{{ }}
$$

Keterangan: $\mathrm{i}=1,2,3, \ldots \mathrm{n}$; dengan $\sum \mathrm{wj}$ $=1$.

wj merupakan nilai pangkat dalam sebuah atribut dalam sebuah product. Selanjutnya proses dilanjutkan untuk mencari ini preverensi (Vi) untuk mendapatkan hasil berupa perangkingan alternative dengan rumus seagai berikut.

$$
v_{i}=\frac{\prod_{j=1}^{n} X_{i j}{ }^{w_{j}}}{\prod_{j=1}^{n}\left(x_{i j}{ }^{*}\right)^{w_{j}}}
$$

Hasil preferensi (Vi) menunjukkan tingkat keterpilihan sebuah alternatif dengan nilai terkecil dan terdndah.

\section{METODE}

Penelitian dilaksanakan pada kelompok tani rawang dengan jumlah responden sebanyak 5 orang yang bepengalaman dibidangnya. Adapun kerangka kerja dari penelitian ini yaitu 
DOI: https://doi.org/10.33330/jurteksi.v6i2.596

Available online at http://jurnal.stmikroyal.ac.id/index.php/jurteksi

sebagai berikut:

1. Studi Pustaka

Kajian pustaka dimaksudkan untuk mempelajari dan memahami ruang lingkup permasalahan benih cabai. Bahan kajian yang digunakan adalah publikasi karya ilmiah jurnal dan prosiding, buku referensi dan sumber lainnya.

2. Penyusunan Instrumen

Penyusunan instrumen didasarkan pada studi pustaka dan pendapat para pakar. Selanjutnya dilakukan pengu-jian istrumen untuk mendapatkan instrument yang valid dan reliable.

3. Pengumpulan Data

Pengumpulan data ini terkait dengan permasalahan melalui observasi, pengisian angket dan wawancara yang akan diberikan kepada para pakar yang memahami kriteria dan alternatif benih cabai yang unggul yang akan dianalisis.

4. Analisis Data

Analisis dilakukan melalui kombinasi 2 metode SPK yaitu AHP aan WP. AHP untuk mendapatkan informasi berupa kriteria yang paling dominan dalam pemilihan benih cabai terbaik. selanjutnya metode WP untuk mendapatkan nilai preferensi dari alternatif yang disusun dalam bentuk perangkingan.

\section{HASIL DAN PEMBAHASAN}

$\begin{array}{ccc}\text { Berangkat dari } & \text { hasil } \\ \text { pengumpulan data yang telah }\end{array}$ dilaksanakan, ada beberapa kiriteria dari pemilihan benih cabai unggul yang akan diterapkan ke dalam metode AHP sebagai berikut:
Tabel 1. Kriteria Bibit Cabai

\begin{tabular}{cll}
\hline Kriteria & Keterangan & Jenis \\
\hline C1 & Harga Bibit & Cost \\
C2 & Masa Panen & Benefit \\
C3 & Panjang Buah & Benefit \\
C4 & Berat Buah & Benefit \\
C5 & Penyakit & Cost \\
C6 & Cabang & Benefit \\
\hline
\end{tabular}

Langkah selanjutnya dalam menganalisa data kriteria yang telah dikumpulkan tersebut diawali dengan membentuk matriks perbandingan kriteria berikut :

Tabel 2. Matriks Perbandingan Kriteria

\begin{tabular}{ccccccc}
\hline & C1 & C2 & C3 & C4 & C5 & C6 \\
\hline C1 & 1,000 & 7,000 & 2,000 & 8,000 & 0,500 & 6,000 \\
C2 & 0,143 & 1,000 & 0,167 & 2,000 & 0,125 & 0,500 \\
C3 & 0,500 & 6,000 & 1,000 & 7,000 & 0,333 & 4,000 \\
C4 & 0,125 & 0,500 & 0,143 & 1,000 & 0,125 & 0,333 \\
C5 & 2,000 & 8,000 & 3,000 & 8,000 & 1,000 & 7,000 \\
C6 & 0,167 & 2,000 & 0,250 & 3,000 & 0,143 & 1,000 \\
& 3,935 & 24,500 & 6,560 & 29,000 & 2,226 & 18,833 \\
\hline
\end{tabular}

Selanjutnya melakukan perhitungan setiap elemen dengan jumlah elemen dan rata-rata yang membentuk tabel sintesis yang akan dijadikan landasan dalam melakukan perankingan kriteria berikut ini. 
JURTEKSI (Jurnal Teknologi dan Sistem Informasi)

Vol. 6 No. 2, April 2020, hlm. 117 - 124

DOI: https://doi.org/10.33330/jurteksi.v6i2.596

Available online at http://jurnal.stmikroyal.ac.id/index.php/jurteksi
ISSN 2407-1811 (Print)

ISSN 2550-0201 (Online)

Tabel 3. Sistesis Perbandingan Kriteria

\begin{tabular}{cccccccc}
\hline \multicolumn{4}{c}{ Jumlah Setiap Elemen } & & Jumlah & $\begin{array}{c}\text { Rata- } \\
\text { Rata }\end{array}$ \\
\hline 0,254 & 0,286 & 0,305 & 0,276 & 0,225 & 0,319 & 1,664 & 0,277 \\
0,036 & 0,041 & 0,025 & 0,069 & 0,056 & 0,027 & 0,254 & 0,042 \\
0,127 & 0,245 & 0,152 & 0,241 & 0,150 & 0,212 & 1,128 & 0,188 \\
0,032 & 0,020 & 0,022 & 0,034 & 0,056 & 0,018 & 0,182 & 0,030 \\
0,508 & 0,327 & 0,457 & 0,276 & 0,449 & 0,372 & 2,389 & 0,398 \\
0,042 & 0,082 & 0,038 & 0,103 & 0,064 & 0,053 & 0,383 & 0,064
\end{tabular}

Langkah selanjutnya melakukan yaitu perhitungan Consistensi Rasio (CR). CI $=(\lambda$ maks- $n) / n$, Di mana $n=$ banyaknya elemen

$\lambda$ maks $=(3,935 * 0,277)+(24,500 * 0,042)+$

$(6,560 * 0,188)+(29,000 * 0,030)+$

$(2,226 * 0,398)+(18,833 * 0,064)$

$$
=6,332
$$

$\mathrm{n} \quad=6$

$\mathrm{CI}=(6,331-6) /(6-1)=0,066$

IR $=1,24$ karena $\mathrm{n}=6$

$\mathrm{CR} \quad=\mathrm{CI} / \mathrm{IR}=0,066 / 1,24=0,053$

Mengacu pada hasil penemuan

$\mathrm{CR}=0,053$ di atas, maka nilai ketentuan bahwa $\mathrm{CR}<0,1$ dapat dipenuhi sehingg proses analisa prioritas kriteria yang mempengaruhi pemilihan benih cabai unggul dikatakan konsisten.

Hasil perhitungan dari metode AHP diatas dalam bentuk faktor prioritas akan menjadi bobot preferensi dari metode WP. Langkah penelitian selanjutnya adalah menentukan alternatif-alternatif benih cabai unggul dan kriteria sebelumnya untuk mendapat benih cabai unggul.

Tabel 4. Nilai Alternatif Kriteria

\begin{tabular}{ccccccc}
\hline & C1 & C2 & C3 & C4 & C5 & C6 \\
\hline A1 & 4 & 5 & 5 & 3 & 5 & 3 \\
A2 & 3 & 4 & 5 & 3 & 5 & 2 \\
A3 & 5 & 5 & 3 & 2 & 3 & 3 \\
A4 & 3 & 5 & 5 & 2 & 3 & 2 \\
A5 & 3 & 4 & 4 & 5 & 3 & 5 \\
A6 & 5 & 3 & 4 & 5 & 5 & 5 \\
A7 & 4 & 2 & 3 & 3 & 5 & 2 \\
A8 & 2 & 3 & 4 & 4 & 5 & 4 \\
\hline
\end{tabular}

Tabel 5. Bobot Preferensi

\begin{tabular}{ccccccc}
\hline C1 & C2 & C3 & C4 & C5 & C6 & Wj \\
\hline 0,277 & 0,042 & 0,188 & 0,030 & 0,398 & 0,064 & 1,000 \\
\hline
\end{tabular}


DOI: https://doi.org/10.33330/jurteksi.v6i2.596

Available online at http://jurnal.stmikroyal.ac.id/index.php/jurteksi

Langkah selanjutnya menghitung nilai vektor $S$, prosesnya dimulai dari memang-katkan bobot kriteria dan mengalikan bobot preferensi masingmasing yaitu sebagai berikut dengan inisial masing-masing alternatif $\mathrm{S} 1$ sampai S8

$$
\begin{aligned}
\mathrm{S} 1= & \left(4^{0,277}\right) *\left(5^{0,042}\right) *\left(5^{0,188}\right) *\left(3^{0,030}\right)^{*} \\
& \left(5^{0,398}\right) *\left(3^{0,064}\right) \\
= & 0,576 \\
\mathrm{~S} 2= & \left(3^{0,277}\right) *\left(4^{0,042}\right)^{*}\left(5^{0,188}\right) *\left(3^{0,030}\right)^{*} \\
& \left(5^{0,398}\right) *\left(2^{0,064}\right) \\
= & 0,602 \\
\mathrm{~S} 3= & \left(5^{0,277}\right) *\left(5^{0,042}\right) *\left(3^{0,188}\right) *\left(2^{0,030}\right)^{*} \\
& \left(3^{0,398}\right) *\left(3^{0,064}\right) \\
= & 0,596 \\
\mathrm{~S} 4= & \left(3^{0,277}\right) *\left(5^{0,042}\right) *\left(5^{0,188}\right) *\left(2^{0,030}\right)^{*} \\
& \left(3^{0,398}\right) *\left(2^{0,064}\right) \\
= & 0,736 \\
\mathrm{~S} 5= & \left(3^{0,277}\right) *\left(4^{0,042}\right) *\left(4^{0,188}\right) *\left(5^{0,030}\right)^{*} \\
& \left(3^{0,398}\right) *\left(5^{0,064}\right) \\
= & 0,762 \\
\text { S6 }= & \left(5^{0,277}\right) *\left(3^{0,042}\right) *\left(4^{0,188}\right) *\left(5^{0,030}\right)^{*} \\
& \left(5^{0,398}\right) *\left(5^{0,064}\right) \\
= & 0,533 \\
\text { S7 }= & \left(4^{0,277}\right) *\left(2^{0,042}\right)^{*} *\left(3^{0,188}\right) *\left(3^{0,030}\right)^{*} \\
& \left(5^{0,398}\right) *\left(2^{0,064}\right) \\
= & 0,491 \\
\text { S8 }= & \left(2^{0,277}\right) *\left(3^{0,042}\right)^{*} *\left(4^{0,188}\right) *\left(4^{0,030}\right)^{*} \\
& \left(5^{0,398}\right) *\left(4^{0,064}\right) \\
= & 0.673 \\
&
\end{aligned}
$$

Maka dari hasil perhitungan di atas, terbentuklah tabel nilai vektor $\mathrm{S}$ berikut

\section{Tabel 6. Nilai Vektor $S$}

\begin{tabular}{cc}
\hline Nilai Vektor $\mathbf{S}$ & Hasil \\
\hline $\mathrm{S}_{1}$ & 0,576 \\
$\mathrm{~S}_{2}$ & 0,602 \\
$\mathrm{~S}_{3}$ & 0,596 \\
$\mathrm{~S}_{4}$ & 0,736 \\
$\mathrm{~S}_{5}$ & 0,762 \\
$\mathrm{~S}_{6}$ & 0,533 \\
$\mathrm{~S}_{7}$ & 0,491 \\
$\mathrm{~S}_{8}$ & 0,673 \\
\hline
\end{tabular}

Langkah akhir menghitung nilai vektor tersebut yang akan digunakan untuk menghitung preferensi (Vi) untuk proses perankingan. Perhitungan tersebut seperti di bawah ini:

$$
\begin{gathered}
V 1=0,576 /(0,576+0,602+0,596 \\
+0,736+0,762 \\
+0,533+0,491 \\
+0,673) \\
=0,116 \quad \\
V 2=0,602 /(0,576+0,602+0,596 \\
+0,736+0,762 \\
+0,533+0,491 \\
+0,673)
\end{gathered}
$$$$
=0,121
$$

$$
\begin{aligned}
V 3=0,596 /( & 0,576+0,602+0,596 \\
& +0,736+0,762 \\
& +0,533+0,491 \\
& +0,673)
\end{aligned}
$$$$
=0,120
$$$$
V 4=0,736 /(0,576+0,602+0,596
$$$$
+0,736+0,762
$$$$
+0,533+0,491
$$

$$
=0,148
$$

$$
+0,673 \text { ) }
$$

$$
\begin{aligned}
V 5=0,762 /( & 0,576+0,602+0,596 \\
& +0,736+0,762 \\
& +0,533+0,491 \\
& +0,673)
\end{aligned}
$$

$$
=0,53
$$

$$
\begin{aligned}
& V 6=0,533 /(0,576+0,602+0,596 \\
& +0,736+0,762 \\
& +0,533+0,491 \\
& +0,673 \text { ) } \\
& =0,107 \\
& V 7=0,491 /(0,576+0,602+0,596 \\
& +0,736+0,762 \\
& +0,533+0,491 \\
& =0,099 \\
& +0,673) \\
& V 8=0,673 /(0,576+0,602+0,596 \\
& +0,736+0,762 \\
& +0,533+0,491 \\
& +0,673) \\
& =0,135
\end{aligned}
$$


Maka dari hasil perhitungan diatas proses perankingan dengan metode WP sebagai berikut :

Tabel 7. Perankingan

\begin{tabular}{ccc}
\hline Vektor & Hasil & Ranking \\
\hline $\mathrm{V}_{1}$ & 0,116 & 6 \\
$\mathrm{~V}_{2}$ & 0,121 & 4 \\
$\mathrm{~V}_{3}$ & 0,120 & 5 \\
$\mathrm{~V}_{4}$ & 0,148 & 2 \\
$\mathrm{~V}_{5}$ & 0,153 & 1 \\
$\mathrm{~V}_{6}$ & 0,107 & 7 \\
$\mathrm{~V}_{7}$ & 0,099 & 8 \\
$\mathrm{~V}_{8}$ & 0,135 & 3 \\
\hline Berdasarkan & hasil & perhitungan \\
preferensi pada tabel 7, secara berurut \\
alternatifyang terbaik adalah A5, A4, \\
A8, A2, A3, A1, A6, dan A7.
\end{tabular}

\section{SIMPULAN}

Adapun simpulan dari proses penelitian ini adalah Penerapan metode AHP dapat membantu menganalisis kriteria prioritas yang konsisten dalam pemilihan benih cabai unggul. Berdasarkan hasil analisispemilihan benih cabai unggul, metode WP telah berhasil menentukan alternatif terbaik berdasarkan faktor prioritas pemilihan benih cabai unggul melalui penerapan metode AHP sebelumnya. Alternatif yang terbaik dan menghasilkan nilai paling tertinggi dengan nilai vektor 0,153 merupakan benih cabai yang paling unggul.

\section{UCAPAN TERIMA KASIH}

Penelitian ini dibiayai sepenuhnya oleh Kementerian Riset Dan Teknologi/Badan Riset Dan Inovasi Nasional melalui Deputi Bidang Penguatan Riset Dan Pengembangan
Sesuai dengan Kontrak Penelitian Tahun Anggaran 2020.

\section{DAFTAR PUSTAKA}

[1] R. A. Simanjorang, "PENGARUH KONSENTRASI CMCDAN LAMA PENCELUPAN PADA APLIKASI LIDAH BUAYA (Aloe vera L.) SEBAGAI EDIBLE COATING PADA CABAI MERAH (Capsicum annum L.)," J. Ilm. Mahasiswa, Univ. lampung, pp. 1-53, 2017.

[2] Y. Rachmawati, "Analisis Pengaruh Produksi dan Konsumsi Terhadap Harga Cabai Merah di Sumatera Utara," $J$. Bis-A J. Bisnis Adm., vol. 8, no. 1, pp. 83-86, 2019.

[3] P. Puspitawati, N. Hasanah, A. Febriyani, and D. Andriansyah, Kearifan Lokal Petani Kopi Dataran Tinggi Gayo. Yayasan Kita Menulis, 2020.

[4] Z. Azhar and M. Handayani, "Analisis Faktor Prioritas Dalam Pemilihan Perumahan $\mathrm{Kpr}$ Menggunakan Metode Ahp," $J$. Manaj. Inform. dan Sist. Inf., vol. 1, no. 2, p. 19, 2018.

[5] A. Ahmadi and D. T. Wiyanti, "Implementasi Weighted Product ( WP ) dalam Penentuan Penerima Bantuan Langsung Masyarakat PNPM Mandiri Perdesaan," Semin. Nas. Apl. Teknol. Inf., pp. 19-22, 2014.

[6] R. Rustam and R. A. Aziz, "MODEL PENGAMBILAN KEPUTUSAN PENERIMA BANTUAN RASKIN MENGUNAKAN METODE WEIGHTED PRODUCT (WP) 
DOI: https://doi.org/10.33330/jurteksi.v6i2.596

Available online at http://jurnal.stmikroyal.ac.id/index.php/jurteksi

DAN TOPSIS," J. Inf. dan Komput., vol. 7, no. 2, pp. 19-30, 2019.

[7] K

Sukiyono, "file://C:/Users/asus/Downloads/ 51-146-4-PB.pdf," J. Agro Ekon., vol. 23, no. 2, p. 176, 2016.

[8] M. A. Sembiring, "Penerapan Metode Simple Additive Weighting Sebagai Strategi Pembinaan Kecerdasan Anak," Jurteksi, vol. 4, no. 1, pp. 65-70, 2017.
[9] H. Nurdiyanto and H. Meilia, "Sistem Pendukung Keputusan Penentuan Prioritas Pengembangan Industri Kecil Dan Menengah Di Lampung Tengah Menggunakan Analitical Hierarchy Process (Ahp)," Semnasteknomedia Online, vol. 4, no. 1, pp. 3-3-37, 2016.

[10] M. Muslihudin and T. F. Abdillah, "Jurnal TAM.," J. TAM (Technology Accept. Model., vol. 2, no. 0, pp. 26-32, 2017. 